\title{
Transverse Variation of Food Compositions of Corbicula bivalves in a Tidal River with Series of Groins
}

\author{
Nannan Li ${ }^{1}$, Takashi Tashiro ${ }^{2 *}$, Tetsuro Tsujimoto ${ }^{3}$ \\ ${ }^{1}$ Graduate School of Environmental Studies, Nagoya University, Nagoya City, Japan \\ ${ }^{2}$ Disaster Mitigation Research Center, Nagoya University, Nagoya City, Japan \\ ${ }^{3}$ Graduate School of Engineering, Nagoya University, Nagoya City, Japan \\ Email: *ttashiro@nagoya-u.jp
}

Received 23 November 2015; accepted 19 December 2015; published 22 December 2015

Copyright (C) 2015 by authors and Scientific Research Publishing Inc.

This work is licensed under the Creative Commons Attribution International License (CC BY). http://creativecommons.org/licenses/by/4.0/

(c) (i) Open Access

\section{Abstract}

This study was conducted to clarify the food compositions of Corbicula bivalves $(C$. japonica and leana) in tidal rivers with varied landscapes. In order to grasp their trophic structures, we measured the carbon and nitrogen stable isotope ratios of the collected samples such as the bivalves with varied growth stages and the suspended particulate organic matters (SPOMs) with varied landscapes as their food sources, and then analyzed their relationships with IsoSource mixing model software. The stable isotope ratio measurements clarified that there was a large difference in the ranges of $C$. japonica and leana in spite of the same sampling locations, and the IsoSource analysis could quantitatively describe their food compositions. According to the results, it could be clarified that the variations in food compositions were dependent not only on the species difference but also on their growth stages. Furthermore, it might suggest that their diet preferences affected the spatial distributions of these Corbicula bivalves in this location.

\section{Keywords}

Corbicula bivalves, River Estuary, Food Source, IsoSource Mixing Model Software, Stable Isotope

\section{Introduction}

Estuarine zone provides nursery grounds for benthic organisms. Especially, suspended feeding bivalves as a kind of important benthic organism exhibit higher density populations and extremely larger standing stocks of

${ }^{*}$ Corresponding author.

How to cite this paper: Li, N., Tashiro, T. and Tsujimoto, T. (2015) Transverse Variation of Food Compositions of Corbicula bivalves in a Tidal River with Series of Groins. Journal of Water Resource and Protection, 7, 1473-1482. 
biomass compare other common members in estuarine ecosystem [1]. Among various bivalves, Corbicula japonica and leana as the two of three native Corbicula species have been widely recognized in Japan [2]. C. japonica is commonly found in brackish rivers or lakes, while $C$. leana is considered as a freshwater species, and it is reported that the landing of Corbicula species has been decreased [3] [4]. Due to their filter feeding, the nitrogen load from upstream emissions and leaching could be reduced by around 10.7\% [5]. Hence, there are many conventional studies to be treated ecologies and habitat environments of these Corbicula species, in order to conserve their population in estuary environments.

Conventionally, many of the related works have been developed in brackish lakes. Regarding the food sources aspect, the works in brackish lakes (Ogawara and Shinji) showed that these bivalves mainly assimilated autochthonous phytoplankton with their high productivities [3]. However, Kasai and Nakata [6] indicated that C. japonica in river estuary mainly feed on the terrestrial organic matters by using the measurements of carbon and nitrogen stable isotope ratios. And Yamazaki et al. [2] suggested that the C. japonica might shift the habitat in different growth stages. However, there are few reports to compare these two Corbicula species in their food compositions in the same location, and it is also uncertain whether both of them shift food sources with their growing.

The Kiso estuary is one of the most productive for the Corbicula fishery in Japan [2] [3]. The environments in Kiso estuary are characterized by the complex variations in landscapes because of their series of groins longitudinally installed along the one side of the bank [7]. Therefore, in present study, according to measure the stable isotope signatures of $C$. japonica and leana in Kiso estuary, we conduct to clarify the compositions of their food sources along a transverse direction with varied landscapes.

\section{Material and Method}

\subsection{Field Investigation}

Samples were collected from the Kiso estuary which empties in to the Ise Bay of Japan. In the Kiso estuary, a series of groins has been installed along the right bank in the sections located at 12 - 25 river kilometer (R km) from the river mouth since the Meiji era, which has functioned to control the flood flow and to produce diverse landscapes. As the result, embayments have been formed between two adjacent groins due to sediment accumulation and vegetation invasion.

We set three stations along transverse direction in the subtidal zone of Kiso estuary as follows: St. Right (St. R), St. Middle (St. M) and St. Left (St. L) were respectively located at the right bank side (with groins), the thalweg zone and the left bank side (without groins) in the cross-section of $17 \mathrm{R} \mathrm{km} \mathrm{(Figure} 1$ and Figure 2). The details of the sampling designs are listed in Table 1. Potential food sources (SPOMs) were not only collected from $17 \mathrm{R}$ km but also from its upstream (St. U1, U2, U3 and U4) and downstream (St. D1 and D2) area (Table 1).
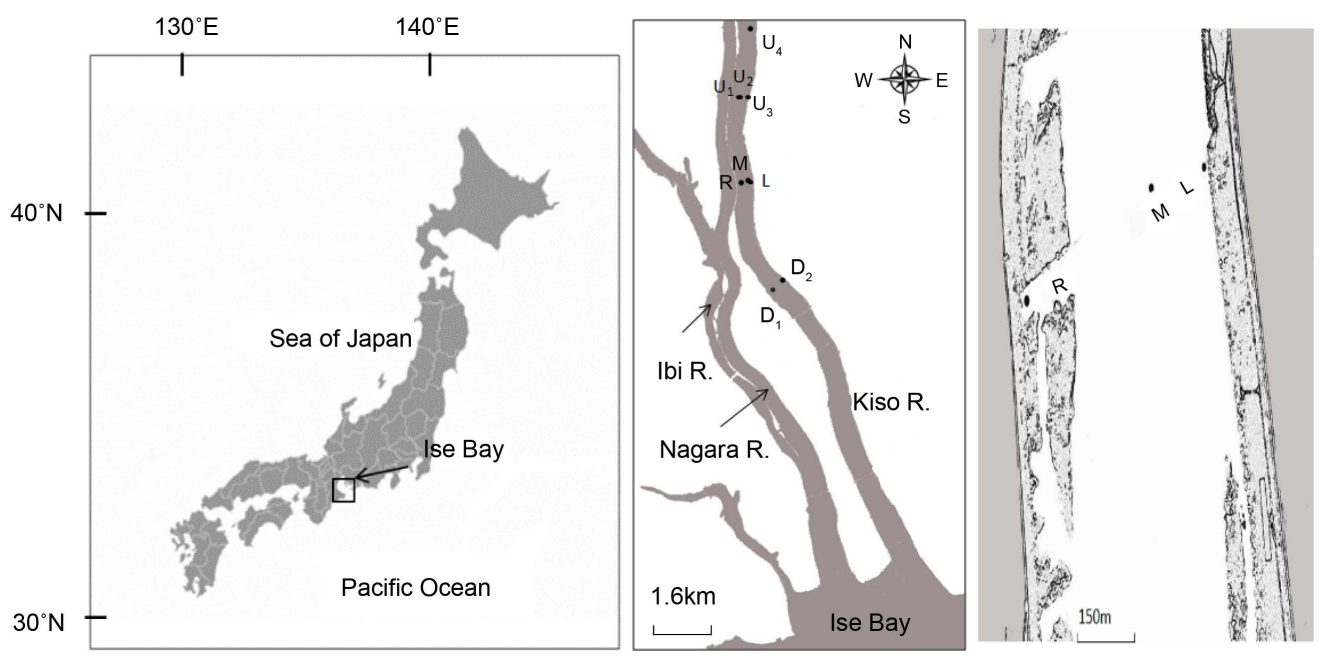

Figure 1. Study locations of Kiso River estuary in Japan. 

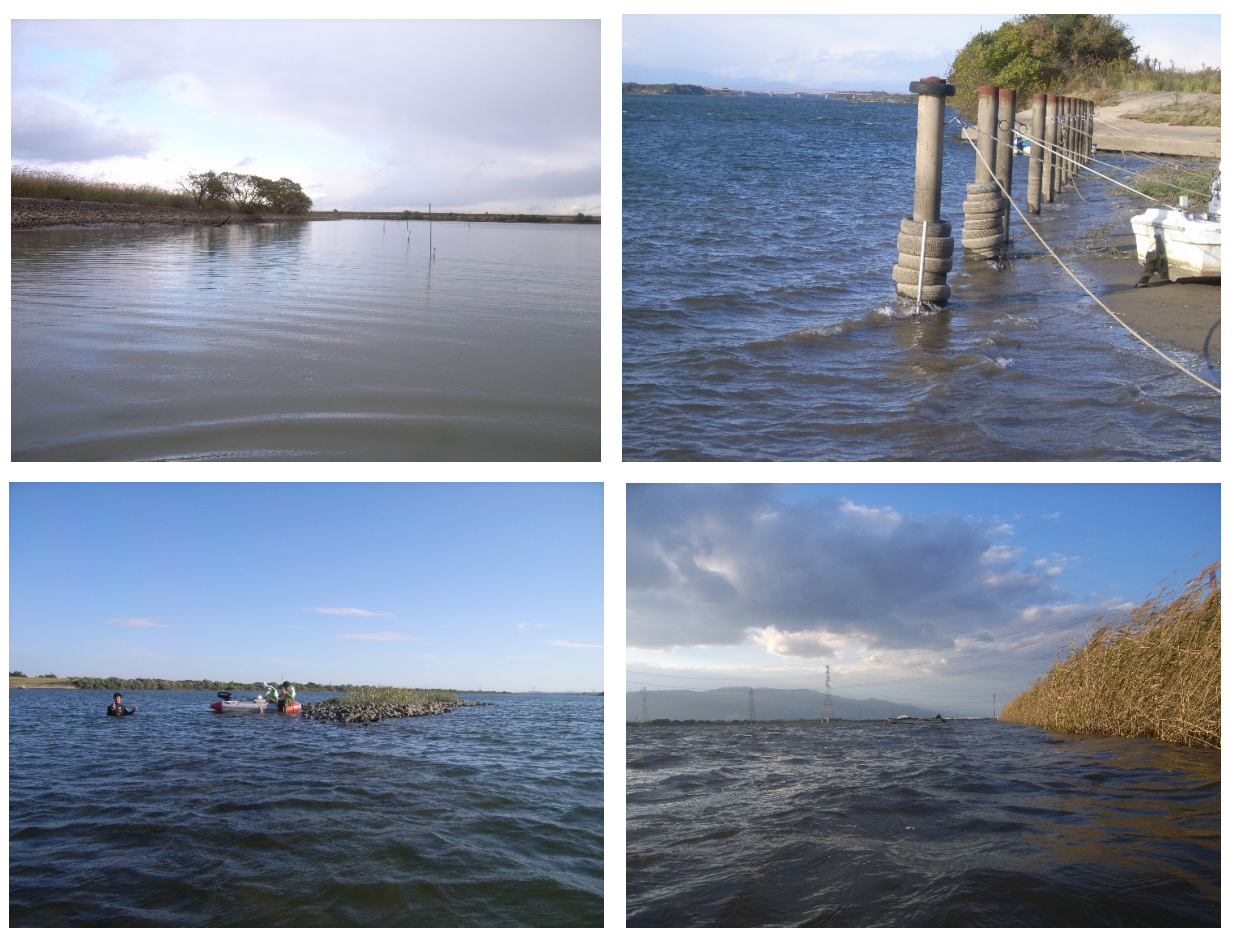

Figure 2. Photographs of sampling stations in typical landscapes. (Upper left: St. R, upper right: St. L, lower left: St. M and lower right: St. D2).

Table 1. Details of sampling designs.

\begin{tabular}{|c|c|c|c|c|c|}
\hline Site & Features & Items & Method & Sampling date & $\begin{array}{l}\text { Location } \\
\text { (river km) }\end{array}$ \\
\hline \multirow[b]{2}{*}{ St. R } & \multirow[b]{2}{*}{ Marge, groins } & Chlorophyll a and salinity & Logging in situ & 2012/11/1-11/15 & \multirow{5}{*}{17.0} \\
\hline & & $\begin{array}{l}\text { Ash free dry mass, carbon and nitrogen } \\
\text { (CN) stable isotope ratio of SPOMs }\end{array}$ & Analyzing in vivo & 2012/11/14 & \\
\hline St. L & Marge, boatslip & $\begin{array}{l}\text { Density, size composition, CN stable } \\
\text { isotope ratio of Corbicula bivalves }\end{array}$ & Analyzing in vivo & 2012/11/14 & \\
\hline \multirow{2}{*}{ St. M } & \multirow{2}{*}{ Thalweg, bar } & $\begin{array}{l}\text { Ash free dry mass, carbon and nitrogen } \\
\text { (CN) stable isotope ratio of SPOMs }\end{array}$ & Analyzing in vivo & 2012/11/14 & \\
\hline & & $\begin{array}{l}\text { Density, size composition, CN stable } \\
\text { isotope ratio of Corbicula bivalves }\end{array}$ & Analyzing in vivo & 2012/11/14 & \\
\hline St. U1 & $\begin{array}{l}\text { Marge, groins, } \\
\text { vegetation }\end{array}$ & Chlorophyll a and salinity & Logging in situ & 2012/11/1-11/15 & \multirow{3}{*}{20.0} \\
\hline St. U2 & Thalweg & $\begin{array}{l}\text { Ash free dry mass, carbon and nitrogen } \\
\text { (CN) stable isotope ratio of SPOMs }\end{array}$ & Analyzing in vivo & $2012 / 10 / 4$ & \\
\hline St. U3 & Marge, boatslip & $\begin{array}{l}\text { Ash free dry mass, carbon and nitrogen } \\
\text { (CN) stable isotope ratio of SPOMs }\end{array}$ & Analyzing in vivo & $2012 / 10 / 4$ & \\
\hline St. U4 & $\begin{array}{l}\text { Marge, } \\
\text { vegetation }\end{array}$ & $\begin{array}{l}\text { Ash free dry mass, carbon and nitrogen } \\
\text { (CN) stable isotope ratio of SPOMs }\end{array}$ & Analyzing in vivo & 2012/6/7 & 24.0 \\
\hline St. D1 & Marge, groins & Chlorophyll a and salinity & Logging in situ & 2012/11/1-11/15 & \multirow[b]{2}{*}{12.0} \\
\hline St. D2 & $\begin{array}{l}\text { Marge, } \\
\text { vegetation }\end{array}$ & $\begin{array}{l}\text { Ash free dry mass, carbon and nitrogen } \\
\text { (CN) stable isotope ratio of SPOMs }\end{array}$ & Analyzing in vivo & 2012/11/1 & \\
\hline
\end{tabular}

The salinity, chlorophyll a concentration (Chl. a) were logged with salinometer, turbidity meter and water depth gauges (COMPACT-CT, -CLW and -TD, JFE Advantech Co., Ltd.). The data were gathered every 5 minutes during a series of tidal motion. The logged data (salinity and Chl. a) was pooled to get daily average values and to estimate its mean values in a periodical tidal duration (14 days). Substrate samples for analyzing or- 
ganic contents and Corbicula bivalves were gathered with the Ekman-Birge grab (area $=0.0225 \mathrm{~m}^{2}$ ). The SPOM samples were collected by filtering a certain volume of water $(25 \mu \mathrm{m}$ mesh, $2000 \mathrm{~L})$, sealed in a plastic bottle. These collected data are a part of our conventional works [7].

\subsection{Laboratory Procedure}

Benthic organisms were separated from each of the substrate content. Individuals of Corbicula japonica and Corbicula leana were identified and were estimated their numbers and measured their sizes. Then we divided them into each class of the following three groups [7] as L size $\geq 15 \mathrm{~mm}, 7 \mathrm{~mm} \leq \mathrm{M}$ size $\leq 15 \mathrm{~mm}$, and S size $\leq$ $7 \mathrm{~mm}$. We estimated the density of each size of the bivalves in all stations. To measure the stable isotope ratios of carbon and nitrogen of these individuals, the tissues of them were dried and removed fat by according to the conventional method [8], then were analyzed with the Flashy EA1112-DELTAV ADVANTAGE ConFloIV System (EA-IRMS) (Thermo Fisher Scientific Inc.).

Sampled SPOMs were divided into two parts. One was used to estimate their concentrations by ash free dry mass (AFDM), according to Biggs and Karloy [9]. They were separated from samples by GF/B glass-fiber filters (0.47 mm Whatman Janan Ltd., Tokyo), dried with thermostat at $105^{\circ} \mathrm{C}$ for $24 \mathrm{hrs}$, and measured their dry mass. Their AFDM were estimated by lost contents with a muffle furnace (MPN-310, Shimadzu Rika Co., Ltd.) at $400^{\circ} \mathrm{C}$ for $4 \mathrm{hrs}$. The other was pretreated and was measured stable isotope ratios of carbon and nitrogen [8] similar as the bivalve samples. The $\delta^{13} \mathrm{C}$ and $\delta^{15} \mathrm{~N}$ are expressed by the standard $\delta$ notation as follows:

$$
\delta \mathrm{X}=[(\text { Rsample } / \text { Rstandard })-1] \times 10^{3}
$$

where $\mathrm{X}$ is either ${ }^{13} \mathrm{C}$ or ${ }^{15} \mathrm{~N}$, and $\mathrm{R}$ is ${ }^{13} \mathrm{C} /{ }^{12} \mathrm{C}$ for carbon and ${ }^{15} \mathrm{~N} /{ }^{14} \mathrm{~N}$ for nitrogen. Pee Dee Belemnite and atmospheric nitrogen were used as the isotope standards for carbon and nitrogen, respectively. Also, we sampled culms or leaves of typical terrestrial plants such as reeds and willows in each of the stations, to measure their stable isotope ratios. Moreover, the Cluster analysis (with Euclidean distance and Ward's method) was conducted to categorize the SPOM variations with stable isotope ratios.

\subsection{Data Analysis}

Student's t test was conducted to determine whether there were significant differences in physical items between Sts. R and L. Two-way analyses of variance (ANOVA) were used to test the effects of the size (L, M and S) and transverse location (St. R, St. M and St. L) on the density of each of the bivalves. If there were any significant differences in each of the variables, the Scheffe's $F$ tests were run to confirm where the differences occurred between groups.

The IsoSource (ver. 1.3.1) software [10] was used to determine the percentage of contribution of each of the organic matters to the diet of bivalve using both $\delta^{13} \mathrm{C}$ and $\delta^{15} \mathrm{~N}$. All possible combinations of each source contribution $(0 \%-100 \%)$ were examined by small increments $(1 \%-2 \%)$. The incremental parameter was set to $1 \%$, and the tolerance parameter was initially set at $0.1 \%$. If the mixture isotope values were out of bounds, we increased the tolerance parameter by $0.1 \%$ until it reached [11]. In adopting these software, we set the hypothetical food source by giving presumptive $0.8 \%$ trophic shift in the $\delta^{13} \mathrm{C}$ and $3 \%$ shift in the $\delta^{13} \mathrm{~N}$ [12] between potential food sources and the bivalves.

\section{Result and Discussion}

\subsection{Physical Environment Condition}

Because most of the features about physical environment conditions have already described in our previous paper [7], we hereby introduce the items related to the diet conditions. Table 2 shows the concentrations of chlorophyll a, SPOM and salinity in each of the station. According to the Student's t-test results, both of them showed significantly higher values in St. R compare to those in St. L $(P<0.05)$. The SPOM at St. R was also somehow higher than that at St. L. It indicated that habitat environment in St. R is considered to be relatively lentic while that in St. L is considered to be lotic, which are contrasting landscapes due to the series of groins.

\subsection{Distributions of Corbicula bivalves}

Figure 3 shows the density distributions with the three size classes of the C. japonica (a) and leana (b) in each 
Table 2. Concentrations of chlorophyll a, SPOM and salinity.

\begin{tabular}{|c|c|c|c|}
\hline & St. R & St. $M$ & St. L \\
\hline Chl a $(\mu \mathrm{g} / 1)$ & $11.72 \pm 7.28$ & - & $1.13 \pm 0.58$ \\
\hline AFDM of SPOM $\left(\mathrm{mg} / \mathrm{m}^{2}\right)$ & 5.51 & 1.15 & 0.71 \\
\hline Salinity (PSU) & $0.29 \pm 0.55$ & - & $0.04 \pm 0.05$ \\
\hline
\end{tabular}

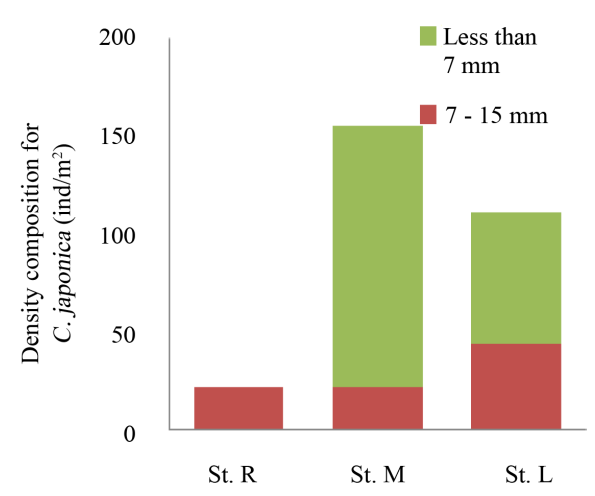

(a)

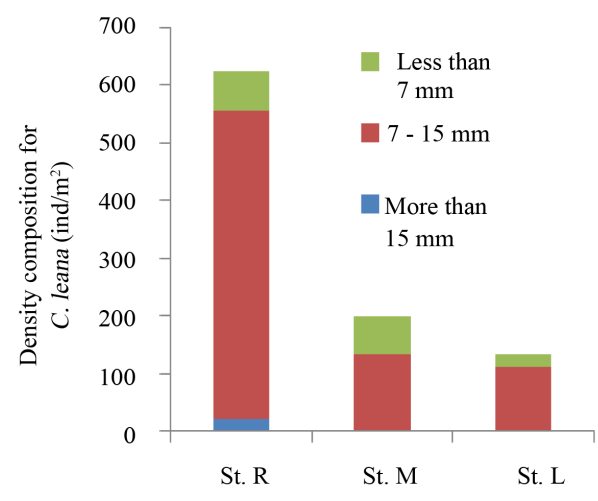

(b)

Figure 3. Density distributions with three size classes of C. japonica (a) and leana (b) in Sts. R, M and L.

of the stations, as they have been shown in our conventional work [7]. Two-way ANOVA results showed that neither size nor the locations significantly influenced density of the bivalves $(P<0.01)$. The total density of $C$. japonica showed lower value in St. $\mathrm{R}$ than the other stations. In contrast, $C$. leana showed much higher density in St. R. Additionally, the C. japonica individuals in St. R were completely composed by the M size ones, however, in Sts. $\mathrm{M}$ and $\mathrm{L}$, those were mainly occupied by the $\mathrm{S}$ size one.

About the $C$. leana individuals, their $\mathrm{M}$ size ones were main components in each of the station. The density of both of the bivalves showed converse result along the transverse direction.

\subsection{Spatial Variation of Stable Isotopic Signatures of SPOMS}

Figure 4 shows the $\delta^{13} \mathrm{C}$ and $\delta^{15} \mathrm{~N}$ plots of SPOMs in all of the collected samplings. The $\delta^{13} \mathrm{C}$ ranged from $-27.76 \%$ to $24.24 \%$, showed a systematic decreased tendency from seaward to landward except some of irregular point such as St. D2 (-27.15\%). In transverse direction, the $\delta^{13} \mathrm{C}$ in the thalweg area (Sts. M and U2), showed relatively higher values than with and without groins area of the same cross-section. In the previous study, marine POM showed significantly higher value of $\delta^{13} \mathrm{C}$ than river and terrestrial POMs [13]. They concluded that the values of $\delta^{13} \mathrm{C}$ were gradually decreasing from seaward to terrestrial side [13]. However, in the current study, considering the different terrain and vegetation distribution between the areas with and without groins, the $\delta^{13} \mathrm{C}$ values of SPOM did not change regularly following the salinity concentration as shown in the conventional report [13]. Additionally, the SPOM showed a wide range of $\delta^{15} \mathrm{~N}$ values ranged from $1.70 \%$ o to $5.01 \%$.

Table 3 shows the results of classification by using the cluster analysis with the carbon and nitrogen stable isotope ratios. The sampled SPOMs were categorized into 4 groups based on Euclidean distance. The group I displayed lower $\delta^{13} \mathrm{C}$ values (-27.15\% - -26.8\%) and more enriched $\delta^{15} \mathrm{~N}$ values $(4.31 \%$ - $5.01 \%$ ) than the other groups. They were similar with the collected samples of reed, $P$. australis $\left(\delta^{13} \mathrm{C}=-27.29 \%\right.$, $\delta 15 \mathrm{~N}=$ $4.95 \%$ o). It means that SPOM of group I might derive from detritus of autochthonous terrestrial vegetation. Both of two samples of the type II were collected from the stations near to the left bank without groins (Sts. L and U3), which showed intermediate values of $\delta^{13} \mathrm{C}(-26.34 \%$ - $-25.70 \%)$ and relatively lower values of $\delta^{15} \mathrm{~N}$ $(3.00 \%$ - 3.53\%). The group III was composed of the data from the area with groins (Sts. R and D1) and thalweg area (Sts. M and U2). Their higher salinity values (Table 2) and relatively enriched values of $\delta^{13} \mathrm{C}$ suggested that the type III was mainly affected by high tide intrusion. The $\delta^{13} \mathrm{C}$-enriched marine organic matter 


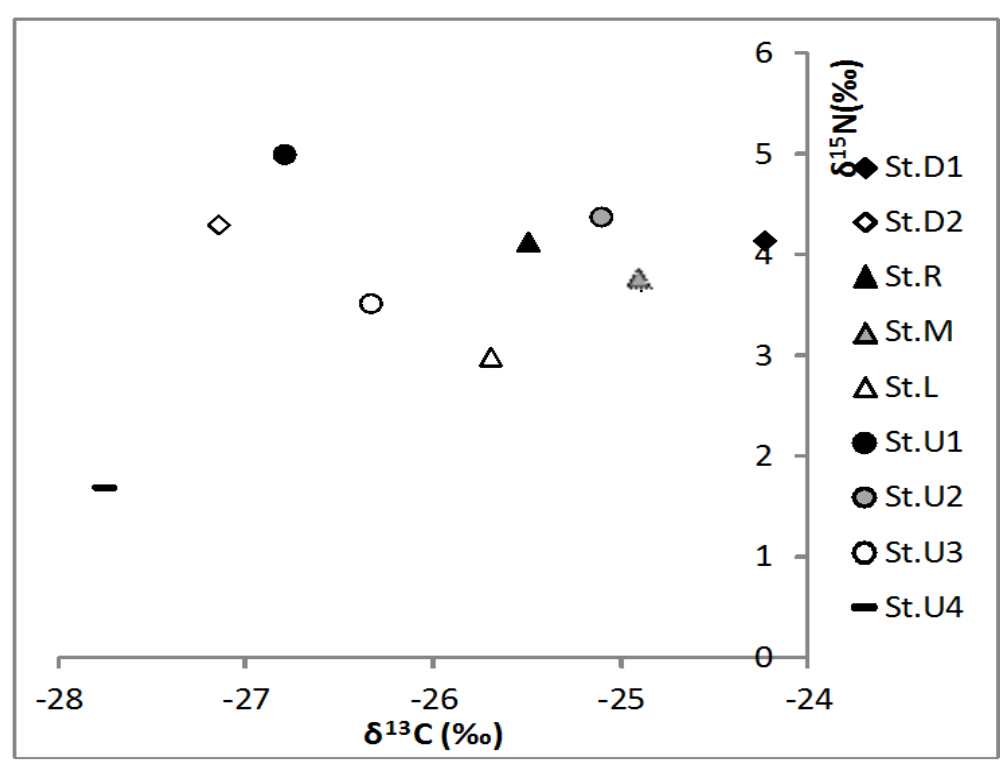

Figure 4. $\delta^{13} \mathrm{C}$ and $\delta^{15} \mathrm{~N}$ plots of potential food sources (SPOMs), collected from Sts. R, M and L; upstream Sts. U1, 2, 3 and 4 and downstream Sts. D1 and 2.

Table 3. SPOM classification by the cluster analysis with euclidean distance depending on $\delta^{13} \mathrm{C}$ and $\delta^{15} \mathrm{~N}$ values.

\begin{tabular}{ccccc}
\hline Group & I & II & III & IV \\
\hline Station & St. D2, St. U1 & St. L, St. U3 & St. D1, St. R, St. M, St. U2 & St. U4 \\
$\delta^{13} \mathrm{C}$ variation & $-27.15--26.8$ & $-26.34--25.70$ & $-25.50--24.24$ & -27.76 \\
$\delta^{15} \mathrm{~N}$ variation & $4.31-5.01$ & $3.00-3.53$ & $3.79-4.39$ & 1.7 \\
\hline
\end{tabular}

brought by the tidal current easily intruded or reserved in these. The type IV collected from the upper estuary (St. U4 in 24R km) showed the lowest values of $\delta^{13} \mathrm{C}(-27.76 \%)$ and $\delta^{15} \mathrm{~N}(1.7 \%)$, which indicated that it was strongly influenced by terrestrial particulate organic matter (TPOM) [13].

According to the result of these classifications, the SPOM collected from Sts. D2, L and U4 were selected as the representative end members of group of I, II and IV, respectively. Although Sts. R and M belonged to the same group III, the SPOMs collected from Sts. R or M were selected as the representative end members of type of III according to the proximity principle. In the food source analysis below, these end members are considered to be used for the estimation with the IsoSource [10].

\subsection{Spatial Variation in Isotopic Signatures for Benthic Bivalves}

Figure 5 shows the $\delta^{13} \mathrm{C}$ and $\delta^{15} \mathrm{~N}$ plots of muscle tissues of $C$. japonica and leana in each of the stations. The $\delta^{13} \mathrm{C}$ of $C$. japonica ranged from $-26.7 \%$ to $-25.81 \%$, while those of $C$. leana showed relatively higher values ranged from $-26.2 \%$ to $-25.0 \%$. The $\delta^{15} \mathrm{~N}$ of $C$. japonica showed narrow range (5.94\%o to $7.00 \%$ ), while $C$. leana showed wider and relatively lower values (3.41\% to 6.68\%). The characteristic of isotope values for these two bivalves suggested that $C$. japonica preferred the organic matter with depleted- $\delta{ }^{13} \mathrm{C}$ and more enriched- $\delta{ }^{15} \mathrm{~N}$ SPOM as the food source compared to $C$. leana in this study area.

Figure 6(a) shows that the $\delta^{13} \mathrm{C}$ and $\delta^{15} \mathrm{~N}$ plots of SPOM end members and C. japonica individuals with these size variations. Both of the hypothetical diets of each of the bivalves and the food source polygon with the end members are drawn in this figure. Their isotope signatures of hypothetical diets were quite different from those of SPOMs in the same location. It suggested that the neighbor SPOM cannot always be used as the essential food source for $C$. japonica in each of the locations. As the isotope signatures of bivalves decreasing from St. R, their hypothetical diets were closer to SPOM of St. D2 and St. U4 indicated the contributions of these two food sources increased from Sts. R to L. We also can infer that SPOMs of Sts. D2 and U4 are the necessary diets, because if one of the SPOM of Sts. D2 and U4 were absent, almost all of the isotope signatures of hypothetical diet 


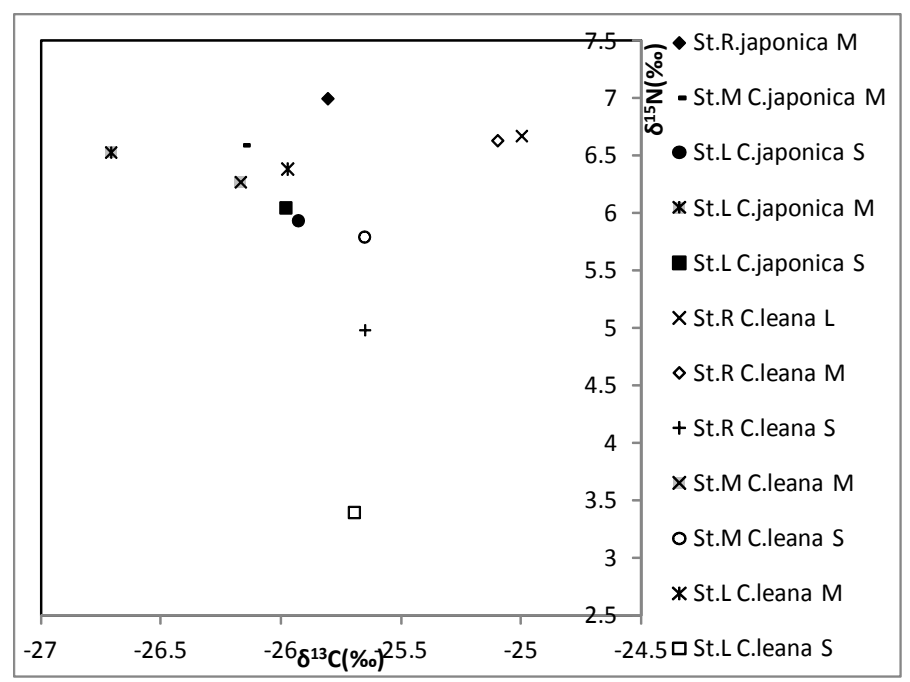

\section{Figure 5. $\delta^{13} \mathrm{C}$ and $\delta^{15} \mathrm{~N}$ plots of $C$. japonica and leana with size classes (S, M and L) in Sts. R, M and L.}

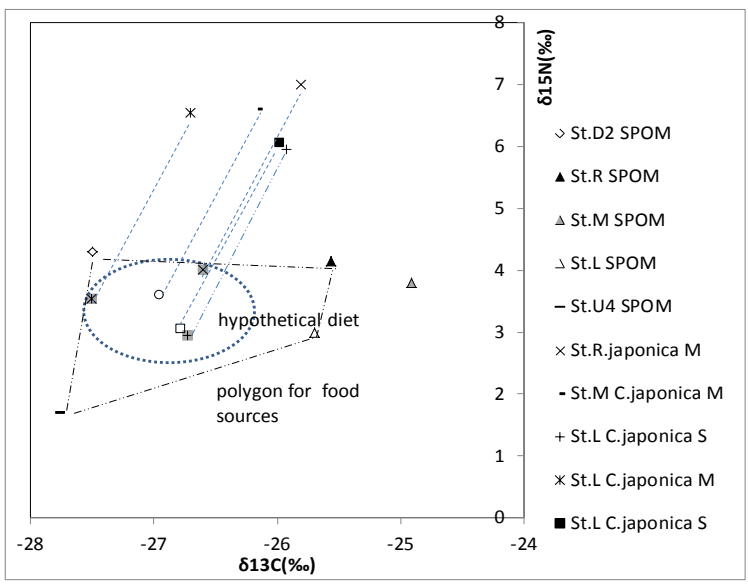

(a)

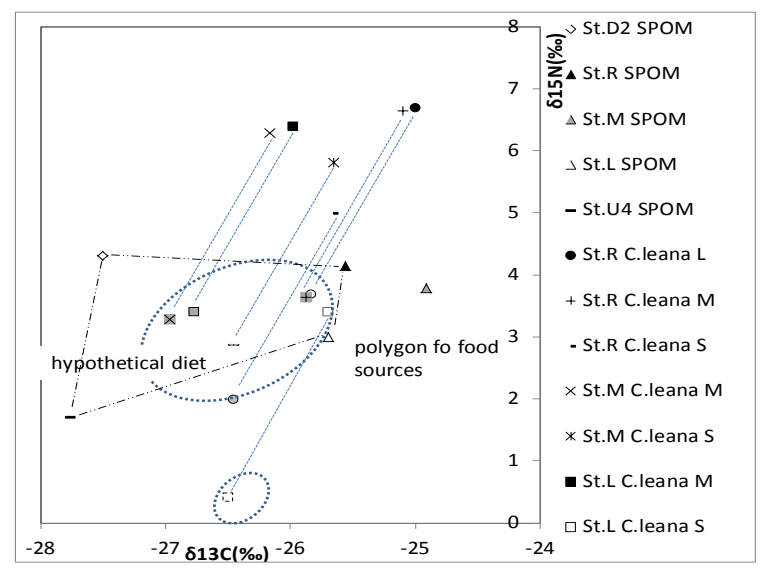

(b)

Figure 6. $\delta^{13} \mathrm{C}$ and $\delta^{15} \mathrm{~N}$ plots of SPOM end members and C. japonica (a) and C. leana (b) with size variations. Hypothetical diets are put a ring around, and connected to each of the bivalves with dotted lines. Food source polygon with the end members are drawn by broken lines.

would outside the convex polygon boundary of the food sources [11]. The S size C. japonica individuals showed relatively lower $\delta^{15} \mathrm{~N}$ values in Sts. M and L than the larger individuals, which implied that they might take relatively depleted $-\delta^{15} \mathrm{~N}$ SPOM was the main diet.

Figure 6(b) shows that the $\delta^{13} \mathrm{C}$ and $\delta^{15} \mathrm{~N}$ plots of SPOM end members and C. leana with size variations. Both of their hypothetical diets and food source polygon with the end members are drawn in the same figure. The $\delta^{13} \mathrm{C}$ and $\delta^{15} \mathrm{~N}$ of $\mathrm{L}$ and $\mathrm{M}$ size individuals of C. leana found in with groin area (St. R) showed the most enriched values $\left(\delta^{13} \mathrm{C}=-25.0 \%\right.$, $\delta^{15} \mathrm{~N}=6.68 \%$; $\delta^{13} \mathrm{C}=-25.1 \%$, $\delta^{15} \mathrm{~N}=6.60 \%$, respectively). The isotope signatures of hypothetical diet of $\mathrm{L}$ and $\mathrm{M}$ size individuals (Figure 6(b), ca. $\delta^{13} \mathrm{C}=-25.8 \%$, $\delta^{15} \mathrm{~N}=3.64 \%$ ) exhibited similar values to St. R (in situ), which suggests that the neighbor SPOM take largest contribution to their food composition. While the $\delta^{13} \mathrm{C}$ and $\delta^{15} \mathrm{~N}$ of hypothetical diets for $\mathrm{M}$ size individuals in Sts. $\mathrm{L}$ and $\mathrm{M}$ were closer to the SPOMs in Sts.U4 and D2, which indicated they were the important food sources. Additionally, the isotope signatures of hypothetical diets for $\mathrm{S}$ size of $C$. leana displayed similar values of $\delta^{13} \mathrm{C}$ (са. $-26.3 \%$ ) in each of the stations, while the $\delta^{15} \mathrm{~N}(0.4 \%$ - $2.80 \%$ ) was relatively lower than the larger individuals (3.40\% $3.68 \%$ ). The plots of hypothetical diets indicated that $C$. leana might shift the food sources depending on growth stages; we could not find the food sources for $\mathrm{S}$ size individuals in the present study because points of 
their isotope signatures were out of food sources of polygon.

\subsection{Food Sources Contribution}

Figure 7 shows that the food compositions (\%) of the SPOM end members for C. japonica (a) and leana (b) in each of the stations. The M size of C. japonica, the SPOM from St. D2 accounted for the largest contribution of the food sources $(40.4 \%-66.6 \%)$, and followed by the SPOM from St. U4 (4.2\% - 32.1\%) in each of the station. The contributions of these two food sources showed an increased tendency from the area with groins (St. R) to that without groins (St. L). Great utilization of $\delta^{13}$ C-depleted SPOM (SPOM of Sts. D2 and U4) in each of the stations indicated that the adult of $C$. japonica might be a selective filter feeder, mainly depended on TPOM. In the area with groins (St. R), water exchange was reduced due to the blocking effect of groins [14], which limited the material transport between the area with groins (St. R) and thalweg zone (St. M). Consequently, their preferable food sources could be prevented into the semi-closed embayment area (St. R), while in the area without groins (St. L), water exchanging supplied the preferable food sources. Additionally, highest concentration of neighbor SPOM (5.51 mg/L, Table 2) corresponded to the lowest density of $C$. japonica bivalves $\left(22.2 \mathrm{ind} / \mathrm{m}^{2}\right.$, Figure 3) in St. R; the lowest concentration of SPOM in Sts. M and L (1.15 and $0.71 \mathrm{mg} / \mathrm{L}$ respectively, Table 2) corresponded to the highest density of $C$. japonica bivalves $\left(155.5 \mathrm{ind} / \mathrm{m}^{2}, 111.1 \mathrm{ind} / \mathrm{m}^{2}\right.$, Figure 3). It also proved that a large amount of $\delta^{13} \mathrm{C}$-enriched SPOM in St. R might not be as an ideal food source for C. japonica. The SPOM which showed depleted $\delta^{13} \mathrm{C}$ value might be the potential food source for $C$. japonica such as terrestrial organic matter. These kinds of processes were also observed in the previous study [6].

Food sources for the S size individuals of $C$. japonica in Sts. M and L showed relatively lower utilization of SPOM from St. D2 (са.24\%) and higher those from St. U4 (са.39\%), while M size individuals suggested that smaller size of $C$. japonica tended to digest and assimilate the food sources with relatively lower $\delta^{15} \mathrm{~N}$. It was supposed that the smaller size of $C$. japonica might have weak capacity in assimilating the SPOM derived from nitrogen-polluted water since increased $\delta^{15} \mathrm{~N}$ value was found in excessive richness of nitrogen loaded water [12].

Regarding the $C$. leana, in St. R, the $\mathrm{L}$ and $\mathrm{M}$ size individuals showed similar food source compositions, mainly depended on the neighbor SPOM which accounted for $60.5 \%$ and $53.2 \%$ respectively. The M size of $C$. leana in Sts. M and L showed similar food compositions, mainly depended on the SPOM from St. D2 (44.6\%, $40.9 \%$ respectively) and St. U4 (28.4\%, 29\% respectively). The adult C. leana completely shifted food compositions between the area with groins (St. R) and the one without groins (St. L), which indicated that adult $C$. leana might be an opportunistic filter feeder. In the area with groins (St. R), dense Chl. a with neighbor abundant SPOM (11.72 $\mu \mathrm{g} / \mathrm{L}, 5.51 \mathrm{mg} / \mathrm{L}$, Table 2) were trapped in this kind of semi-closed area. In this situation, the utilization of the neighbor SPOM was higher. A large quantity of food sources in situ supported approximately 3 times of individuals in Sts. L or M (Figure 3). However, in the area without groins (St. L), due to the bare and relatively open terrain, the primary production might be lower. The Chl. a and SPOM $(1.13 \mu \mathrm{g} / \mathrm{L}, 0.71 \mathrm{mg} / \mathrm{L}$, Table 2) were insufficient and could not provide enough diet. Under this situation, individuals of $C$. leana decreased

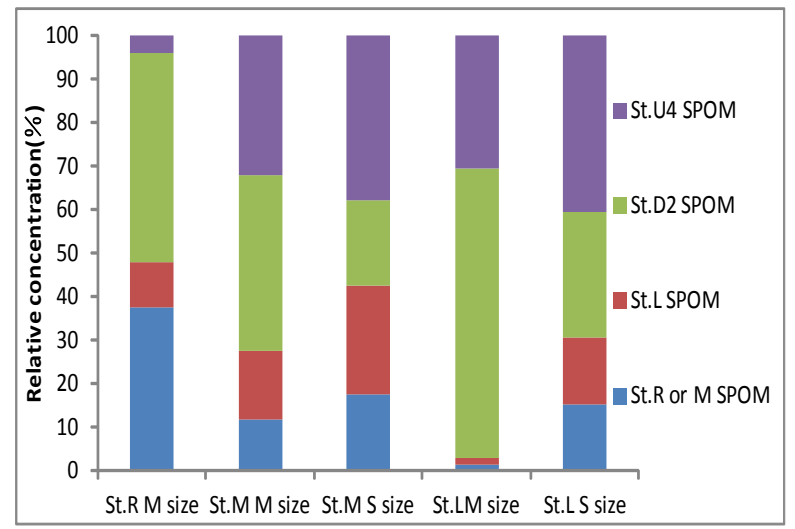

(a)

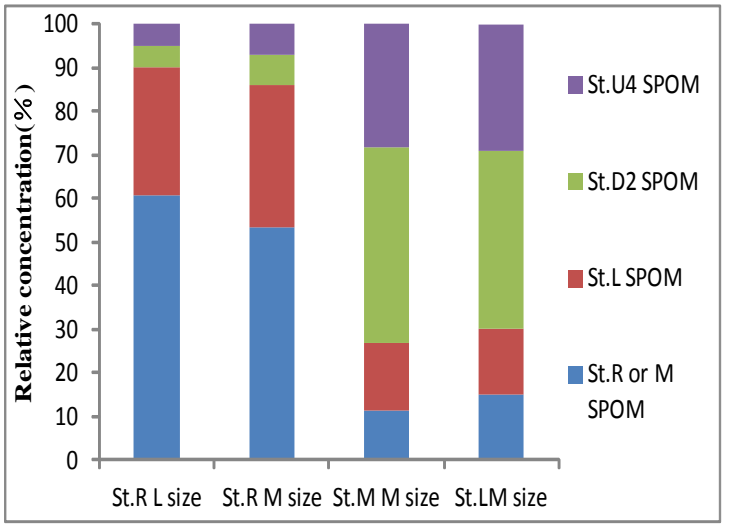

(b)

Figure 7. Food compositions (\%) of the SPOM end members for C. japonica (a) and leana (b) in each of the stations. 
compared with St. R (Figure 3). However, bare terrain also promoted water mixing process between river flow and intruded marine and made food sources diverse. The conventional study concluded that $C$. leana was a fresh water bivalve and selected TPOM as the food source [15]. However, in the present research, the adult $C$. leana was considered as an opportunistic filter feeder as $\delta^{13} \mathrm{C}$ of food source fluctuated from $-27.76 \%$ to $-24.24 \%$; $\delta^{15} \mathrm{~N}$ ranged from $1.70 \%$ to $5.01 \%$.

\section{Conclusions}

This study has treated the conditions of feeding environments of two kinds of Corbicula bivalves in a tidal river with transverse variations by using the ISO Source mixing model [10] with the carbon and nitrogen stable isotope ratios of their potential food sources. According to their results, we could have clarified their food compositions in each growth stage in tidal river with varied landscapes as follows:

The adult of $C$. japonica (L size $\geq 15 \mathrm{~mm}, 7 \mathrm{~mm} \leq \mathrm{M}$ size $\leq 15 \mathrm{~mm}$ ) might be a selective filter feeder, mainly depended on TPOM (SPOM from St. D2 and St. U4). The contributions of this kind of food sources showed an increased tendency from the area with groins (St. R) to that without groins (St. L). The diet for S size individuals of $C$. japonica $(\leq 7 \mathrm{~mm})$ did not show obvious differences from the adult individuals. However, the contribution of $\delta^{13} \mathrm{C}$-depleted SPOM increased in the diet of S size individuals.

The adult $C$. leana might be an opportunistic filter feeder as $\delta^{13} \mathrm{C}$ of food source fluctuated from $-27.76 \%$ to $-24.24 \%$; $\delta^{15} \mathrm{~N}$ ranged from $1.70 \%$ to $5.01 \%$. They completely shifted food compositions between the area with groins (St. R) and the one without groins (St. L). In the area with groins, they mainly depended on the SPOM derived from neighbor water column, which in the area without groins and of thalweg zone, they mainly depended on TPOM due to the fluvial and tidal processes. The $\delta^{15} \mathrm{~N}$ value of hypothetical diet for S size individuals showed $0.88 \%$ - 3.00\% lower than those for the $\mathrm{M}$ and $\mathrm{L}$ size individuals, and could not be explained with the potential food sources which we treated. Therefore, the C. leana individuals might shift their food sources corresponding to each of their growth stages.

These findings in the present study can help to understand the upper estuary ecosystem processes in the water with very low saline condition where there were few conventional works.

\section{Acknowledgements}

The authors would like to express their deepest gratitude to Dr. Yuji Toda, for the technical advices with many crucial comments, and to Mr. Masaaki Yoshimoto and the other members of hydraulic engineering laboratory of Nagoya University, for the heartwarming supports in their field surveys and laboratory analyses.

\section{References}

[1] Komorita, T., Kajihara, R. and Tsutsumi, H. (2014) Food Sources for Ruditapes philippinarum in a Coastal Lagoon Determined by Mass Balance and Stable Isotope Approaches. PLOS ONE, 9, e86732. http://dx.doi.org/10.1371/journal.pone.0086732

[2] Nanbu, R. and Mizuno, T. (2004) Post-Settlement Growth and Mortality of Brackish Water Clam Corbicula japonica in the Kiso Estuaries, Central Japan. Fisheries Science, 74, 1254-1268. http://dx.doi.org/10.1111/j.1444-2906.2008.01650.x

[3] Kasai, A., Toyohara, H., Nakata, A., Miura, T. and Azuma, N. (2006) Food Sources for the Bivalve Corbicula japoni$\mathrm{ca}$ in the Foremost Fishing Lakes Estimated from Stable Isotope Analysis. Fishery Science, 72, 105-114. http://dx.doi.org/10.1111/j.1444-2906.2006.01123.x

[4] Japan Fisheries Resource Conservation Association. "Yamato-shijimi”: Brackish Water Clam. www.fish-jfrca.jp/02/pdf/pamphlet/094

[5] Furuhata, H., Ohno, Y., Tashiro, T., Tsubaki, R. and Tsujimoto, T. (2008) Estimation of Ecosystem Services by Brackish Bivalve in the Kiso River Tidal Reach. Advances in River Engineering, 14, 479-484.

[6] Kasai, A. and Nakata, A. (2005) Utilization of Terrestrial Organic Matter by the Bivalve Corbicula japonica Estimated from Stable Isotope Analysis. Fishery Science, 71, 151-158. http://dx.doi.org/10.1111/j.1444-2906.2005.00942.x

[7] Li, N., Tashiro, T. and Tsujimoto, T. (2015) Habitat and Food Sources of Corbicula bivalves in Tidal River with Serious of Groins. Annual Journal of Hydraulic Engineering, JSCE, 59, 1-6.

[8] Yamada, K., Tashiro, T. and Tsujimoto, T. (2014) Effects of Sediment Replenishment on Stream Ecosystem below Dam and Reservoir: Their Verification with Particulate Organic Matters, Aquatic Organisms and the Stable Isotope 
Ratios of Carbon and Nitrogen. Limnology in Tokai Region of Japan, 64, 11-21 (in Japanese).

[9] Biggs, B.J.F. and Kilroy, C. (2000) Stream Periphyton Monitoring Manual. New Zealand Institute Water and Atmosphere for Ministry for the Environment, Christchurch, New Zealand. http://www.niwa.co.nz/sites/default/files/import/attachments/peri_complete.pdf

[10] Phillips, D.L. and Gregg, J.W. (2003) Source Partitioning Using Stable Isotopes: Coping with Too Many Sources. Oecologia, 136, 261-269. http://dx.doi.org/10.1007/s00442-003-1218-3

[11] Shin, H.S., Amahashi, N. and Mitamura, O. (2013) Trophic Position and Growth Stages of Caddisfly (Stenopsyche marmorata Navas) Larvae in the Echi River, Japan. Limnology, 14, 283-291. http://dx.doi.org/10.1007/s10201-013-0406-Z

[12] Hansson, S., Hobbie, J.E., Elmgren, R. and Larsson, U. (1997) The Stable Nitrogen Isotope Ratio as a Marker of FoodWeb Interactions and Fish Migration. Ecology, 78, 2249-2257. http://dx.doi.org/10.1890/0012-9658(1997)078[2249:TSNIRA]2.0.CO;2

[13] Kasai, A., Horie, H. and Sakamoto, W. (2004) Selection of Food Sources by Ruditapes philippinarum and Mactra veneriformis (Bivalva: Mollusca) Determined from Stable Isotope Analysis. Fisheries Science, 70, 11-20. http://dx.doi.org/10.1111/j.1444-2906.2003.00764.x

[14] Tsubaki, R., Furuhata, H. and Tsujimoto, T. (2008) Flow Structure on Groins during Flood Event and Morphological Evolution of Topography. Annual Journal of Hydraulic Engineering, JSCE, 52, 691-696 (in Japanese). http://dx.doi.org/10.2208/prohe.52.691

[15] Hwang, S.J., Kim, H.S., Shin, J.K., Oh, J.M. and Kong, D.S. (2004) Grazing Effects of a Freshwater Bivalve (Corbicula leana Prime) and Large Zooplankton on Phytoplankton Communities in Two Korean Lakes. Hydrobiologia, 515, 161-179. http://dx.doi.org/10.1023/B:HYDR.0000027327.06471.1e 